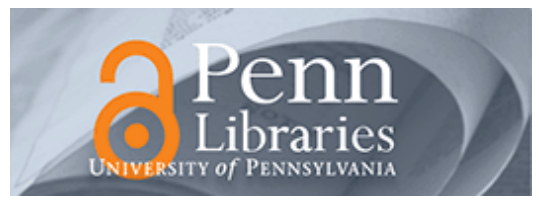

University of Pennsylvania

ScholarlyCommons

Marketing Papers

Wharton Faculty Research

$10-1980$

\title{
Teacher vs. Learner Responsibility in Management Education
}

\section{J. Scott Armstrong}

University of Pennsylvania, armstrong@wharton.upenn.edu

Follow this and additional works at: https://repository.upenn.edu/marketing_papers

Part of the Marketing Commons, and the Other Education Commons

\section{Recommended Citation}

Armstrong, J. S. (1980). Teacher vs. Learner Responsibility in Management Education. 1-18.

http://dx.doi.org/10.2139/ssrn.647802

This paper is posted at ScholarlyCommons. https://repository.upenn.edu/marketing_papers/230

For more information, please contact repository@pobox.upenn.edu. 


\title{
Teacher vs. Learner Responsibility in Management Education
}

\author{
Abstract \\ the traditional strategy in seven field experiments. It produced more than twice as many long-term \\ behavioral changes. It was superior also for attitude change, but not for gains in knowledge.

\section{Keywords} \\ Teaching, teacher, learner, management education, learning behavior changes \\ Disciplines \\ Business | Marketing | Other Education
}

A literature review suggested that behavioral changes occur more rapidly when the learner assumed responsibility. Natural learning, an approach to help learners assume responsibility, was compared with 
Unpublished Working Paper

Teacher vs. Learner Responsibility in Management Education

\author{
J. Scott Armstrong \\ The Wharton School, University of Pennsylvania, Philadelphia, PA \\ October 1980
}

\begin{abstract}
A literature review suggested that behavioral changes occur more rapidly when the learner assumed responsibility. Natural learning, an approach to help learners assume responsibility, was compared with the traditional strategy in seven field experiments. It produced more than twice as many long-term behavioral changes. It was superior also for attitude change, but not for gains in knowledge.
\end{abstract}

This paper describes two strategies for management education: The "traditional" strategy, which places responsibility for learning upon the teacher, and "natural learning," which places responsibility upon the learner. Empirical literature was reviewed to compare these strategies. Further comparisons were made in seven field experiments.

\title{
Description of Educational Strategies
}

The traditional, and most common, approach to management education holds the teacher responsible. Two assumptions are made: first, the teacher knows what's best for the learner; and, second, the learner will change as instructed. The traditional approach does not attempt behavioral change. Direct attempts at change are resisted by students. Instead, the traditional program provides information that might be instrumental in change.

Research from psychology contrasts with the traditional assumptions (e. g.. see reviews by Blumberg, 1968, and Condry, 1977). Change is most likely when those who are changing are responsible for the change. The basic assumptions are: 1) the learner knows what's best, and 2) the learner can change. The objectives go beyond content because people are willing to change their own behavior.

All of us have experienced responsibility for our learning. We used it to learn skills such as speaking our native language and walking. For that reason, the learner-responsible strategy is called "natural learning."

Natural learning is found in training that is skill oriented. For example, athletic training uses it. It is rare in management education.

Many approaches can be used to implement natural learning. Two are described below. The first, "SOS" (self-oriented skill training), is defined by completion of a highly structured written process for learning. The second, the "time contract," provides the learner with responsibility for the expenditure of time. It is less structured than SOS.

\section{The Learning Process}

My review of the literature led to the identification of four steps in learning: setting objectives, selecting and completing learning tasks, reviewing, and applying what was learned. The steps are illustrated in Exhibit 1, with arrows indicating time priorities. 
Exhibit 1

Steps In The Learning Process

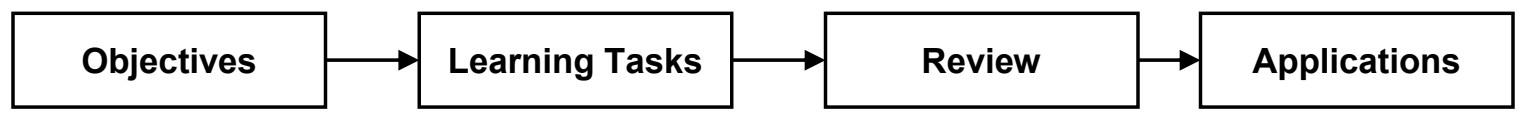

Below, natural learning is contrasted with the traditional approach. for each step in the learning process. (The "teacher's" role differs in natural learning so I use the term "facilitator" there.)

\section{Setting Objectives}

Participants in traditional education typically have ill-defined objectives. They claim to be unable to set specific goals. Instead, they provide vague statements such as "I want to learn more about marketing."

The lack of learner responsibility for selecting objectives is implied by "required courses," and by the finding that participants in advanced management programs seldom select their program: Powell and Davis (1973) found only 60 of the participants selected their management program.

Although teachers in traditional programs are expected to set objectives, this step seldom receives explicit attention. Traditional programs are described by inputs (learning tasks) not outputs (objectives). However, teachers provide explicit objectives in some traditional programs. This increased clarity of objectives should improve learning. Nevertheless, a review of research on explicit objective setting by teachers ("teaching-by-objectives") found little benefit (Duchastel and Merrill, 1973). Clear goals are relevant only if the learner is committed to these goals (Blumberg, 1968; Locke, 1968).

Natural learning calls for commitment by asking the learner to write his/her objectives. The learner is given much freedom in setting objectives. These objectives should be specific (Locke, 1968) and measurable. For measurement of objectives, it helps to concentrate on successes rather than failures. For example, if you want to reduce smoking, McFall (1970) found it was better to measure the times you wanted to smoke but did not (successes), rather than the cigarettes you smoked (failures).

The facilitator does not motivate the learner nor "share responsibility." His role in the objective setting phase is to "listen" and to clarify. He encourages the learner to develop clearly stated and measurable goals.

\section{Selecting and Completing Learning Tasks}

In the traditional program, the teacher is responsible for selecting learning tasks and ensuring that tasks are completed. Tasks focus on content and avoid areas that could cause conflict between teacher and learner. Emphasis is placed on successful performance by participants. Teachers provide positive reinforcement.

The learner should control the selection and performance of the learning tasks (Condry, 1977). Under natural learning, the learner selects tasks. He writes a plan for how much time to spend, and when to start and complete each task.

Experiential exercises are important in natural learning. These use the learner's experience as a base. For example, to help a student with oral communication skills, I ask the student to describe his guidelines for making a presentation; then he makes a presentation. These attitudes and behaviors provide the experiential base.

Lewin's (1952) theory of change is useful in designing experiential exercises. The learner first goes through an unfreezing process, then a change, and finally a refreezing process (see Exhibit 2). For more detail, see Armstrong (1977a). Examples are presented in Armstrong (1976 and 1977b). 
Exhibit 2

Design of an Experiential Exercise

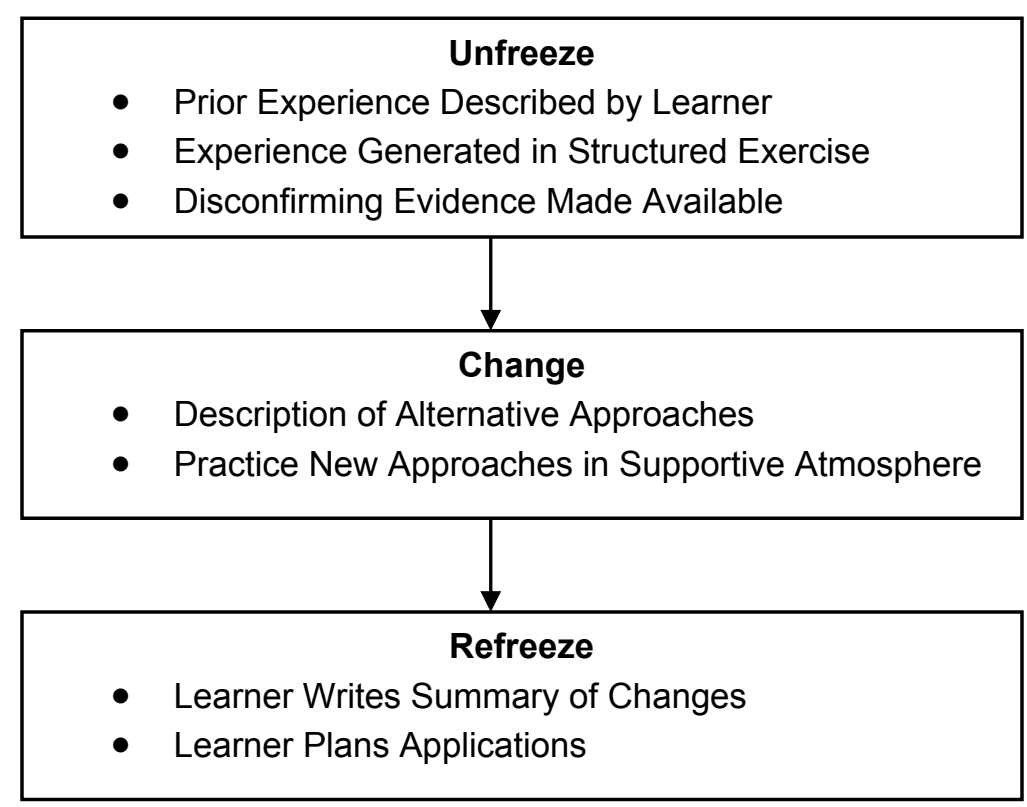

The experiential exercise uses negative reinforcement in the unfreezing phase and positive reinforcement thereafter. Such a strategy is only effective if the learner controls the change process. As a result, experiential exercises should have little value for traditional programs where learner control is absent. Wolfe's (1975) review of the empirical evidence supports this conclusion.

Role playing provides a useful format for the experiential exercise. It reduces the threat from negative feedback. Also, it can be used to support a participant trying new behavior. This use of positive roles (e.g. "imagine you are a successful group leader") is helpful in creating a supportive atmosphere (Colgrove, 1968).

The facilitator suggests tasks that can be used to reach the learner's objectives. He also describes the resources (e.g. time) needed for each task. The task could be for a group or an individual, and it could be self-run or instructor-run. Furthermore, the facilitator should provide an environment where participants can experiment. The facilitator and the other participants should support a learner who practices new behavior (Scott, 1957).

\section{Reviewing Progress}

Knowledge of performance is important to learning (Ammons, 1956). This feedback should go beyond measuring success to provide information on the factors related to success (Newton, 1965).

In the traditional program, exams provide the review. Exams generally measure only success, and success is judged against the teacher's objectives. This review process creates stress. As a result, teachers provide few exams, especially for advanced management programs.

The traditional program ties rewards (grades) to the review. Extensive research spanning half a century (see reviews by Condry, 1977, and Levine and Fasnacht, 1974) shows that extrinsic rewards increase production but decrease learning. With rewards, learners are more "answer oriented" and less "process oriented"; they seek easier tasks, become less logical, and reduce their creativity. Also, extrinsic rewards lessen the learner's subsequent interest in the topic (Lepper, Greene and Nisbett, 1973). 
Under natural learning, the learner is responsible for the review. He writes a specific description after each task about what was learned. This review should tie back to his objectives (Locke, 1968).

The learner takes responsibility for finding something useful in each task. To accomplish this, the learner should not evaluate things outside himself. When one finds fault with others, or with the situation, he loses responsibility for learning something from that task. The facilitator acts as a listener and encourages the learner to avoid evaluation.

\section{Applications}

Learning is of little value until the learner uses what was learned. These applications can be made in courses, on-the-job, or in one's personal life.

Traditional education typically gives no explicit consideration to applications. It assumes the learner will use the knowledge and modify his behavior when needed.

Under natural learning, the learner writes plans for applications. He specifies the behavior (e.g., "I will use visual aids"), the situation ("in my next departmental meeting"), and the time ("by November 21"). Written commitment increases the likelihood of behavior modification (Valiquet, 1968).

Exhibit 3

Descriptions of Traditional and Natural Learning Strategies

\begin{tabular}{lll}
\hline Objectives & \multicolumn{1}{c}{ Traditional } & \multicolumn{1}{c}{ Natural Learning } \\
& X Set by teacher & X Set by learner \\
X Emphasize knowledge & X Emphasize behavior \\
X Not explicit & X Explicit \\
Learning Tasks & X Scheduled by teacher & X Scheduled by learner \\
& X Required & X Optional \\
& X Emphasize success & X Emphasize experimentation \\
X Positive Feedback & X Negative and positive \\
Review & X Directed by teacher & X Directed by learner \\
& X Infrequent & X Frequent \\
Applications & X No explicit plan & X Learner writes plan \\
\hline
\end{tabular}

\section{Previous Research}

The traditional and natural learning strategies were compared by examining published empirical research. Long-term behavioral change was of primary interest. In addition, consideration was given to changes in attitudes and knowledge. Before describing the criteria, consideration is given to the use of participant ratings.

\section{Participant Ratings}

Theoretically, participant ratings of courses have no relationship to learning. High satisfaction might result because the course led to change, or because it reinforced participants' existing knowledge, attitudes, and behavior (Zelby, 1974).

Empirical research on participant satisfaction provided conflicting results. For example, Costin, Greenough, and Menges (1973) concluded from their review that student ratings were valid and reliable, whereas Miller (1978) 
reached the opposite conclusion in his review. Unfortunately, most of the studies examined changes in knowledge, not attitudes or behavior. Three of the more important studies are described here.

Attiyeh and Lumsden (1972) studied economics courses in the U.K.: participant ratings of courses were not related to learning content as measured by "before" and "after" examinations. Rodin and Rodin (1972) compared 11 sections of a calculus course taught by 10 instructors: Participants in sections that rated instructors lower performed better on a common examination. Finally, the Dr. Fox studies showed that high ratings can be obtained with completely meaningless lectures (Naftulin, Ware, and Donnelly, 1973).

Participants' ratings were not used as measures of learning in this paper. They are simply measures of satisfaction. This view is supported for introductory marketing courses, which were used in my experiments. Marks and Molander (1977) found no relationship between participant ratings and knowledge gained.

\section{Changes in Knowledge}

No direct comparisons were found on changes in knowledge for traditional versus natural learning programs. However, much literature assessed the knowledge gain in traditional programs (see reviews by McKeachie, 1969, Dubin and Taveggia, 1968, and Jencks, 1972). Many reviewers concluded that teacher behavior has little impact on learning. For example, students who did not attend class sessions did just as well on exams according to a number of studies. However, Gage's review (1977, pp. 27-41) found some variables did make a difference: For example, lectures were superior to discussions for short-term gains in knowledge; interestingly, this finding was reversed for retention of knowledge.

Even if one method were superior for the transfer of knowledge, this method would not necessarily be superior for attitude or behavior change. For example, Gage (1977, p. 27) found that lectures were inferior to discussions for attitude change.

Do those who learn more content perform better on the job? Hoyt (1966) reviewed studies relating performance in college to achievement on the job in management, teaching, engineering, medicine, and scientific research; his results indicated a negligible relationship between grades and job performance. Price et al (1964), in a study of 500 physicians, found no relationship between academic and job performance. Similar results were obtained for management education by Gutteridge (1973) and Weinstein and Srinivasen (1974).

\section{Attitude Change}

Comparisons between attitude changes in traditional management programs and those in programs containing elements of natural learning were summarized by Miner (1965). 1 reanalyzed this summary using experiments classified as "before-after with control group" and "after only with control group." Eight studies used the traditional strategy while nine used elements of natural learning. Short-term attitude change was found in $67 \%$ of the natural learning programs and $62 \%$ of the traditional programs, an insignificant difference.

Two relevant studies were published since Miner's review. Kolb, Winter, and Berlew (1968) and Kolb and Boyatis (1971) found that participants who set their objectives and made explicit reviews reported more short-term attitude change than a control group. Teachers also reported more change by them.

\section{Behavioral Change}

Although few studies have compared traditional and natural learning strategies, much has been done on the effectiveness of traditional education versus no formal education. These studies suggest the traditional approach has little value for behavioral change. This section summarizes some of the key studies on traditional education.

- Jencks (1972), in his review, concluded that higher education does not improve job skills. 
- Berg (1970) found that workers with more education were slightly less effective in the performance of a variety of jobs (but the differences were not significant).

- Luthans (1969) examined data on marketing personnel in an oil company. Those with more education were rated less promotable at each job level. Also, those educated in business administration were no more-promotable than those educated in liberal arts.

- Baumhart (1968) found that formal education in ethics did not affect the way people said they would act in specific conflict situations in their jobs.

- McCord (1977), in a 35-year follow-up, found that teenage males who received special education were slightly less successful in their careers than an equivalent, randomly selected, sample who had none of this education.

- I reanalyzed data from Miner's (1965) review. Two traditional programs reported no behavioral change, while all six studies using elements of natural learning reported significant long-term behavioral change. This superiority of natural learning was significant $(\mathrm{p}<.05$ using the Fisher Exact Test).

- Schmuck (1968) experimented with a course designed to help junior high school teachers. Some teachers were in a program similar to natural learning as they designed and ran their own experiments. Others participated in traditional learning tasks, primarily discussions. Both groups reported attitude change, but only "natural learning" participants changed their teaching style.

- French, Kay and Meyer (1966) used natural learning principles for on-the-job changes. Managers who wrote objectives, established measures of success, and devised methods for reaching objectives were more successful in changing their behavior than those who were advised by their bosses.

The literature review, along with my judgment, provided hypotheses on the effectiveness of the traditional and natural learning programs for short-term and long-term changes (see Exhibit 4). Of particular interest here is the hypothesis for long-range behavioral change: natural learning is expected to be significantly better than the traditional approach.

\section{Exhibit 4}

Hypotheses on Traditional vs. Natural Learning Strategies

$(1=$ negligible change, to $5=$ large change $)$

\begin{tabular}{lcccc}
\hline & \multicolumn{2}{c}{ Short-term Change } & \multicolumn{2}{c}{ Long-term Change } \\
\cline { 2 - 5 } Level of Change & Traditional Teaching & Natural Learning & Traditional Teaching & Natural Learning \\
\hline Knowledge & 5 & 4 & 3 & 3 \\
Attitudes & 3 & 4 & 2 & 3 \\
Behavior & 2 & 4 & 1 & 3 \\
\hline
\end{tabular}

\section{Field Experiments}

To compare the effectiveness of the traditional and natural learning strategies, I ran seven field experiments from 1974 through 1979. Unfortunately, random assignment of participants was not possible. (According to Walker and Schaffarzick, 1974, this defect is common to almost all educational experiments.) However, I tested alternative explanations by making changes in the various experiments (following the strategy of eclectic research as described in Armstrong, 1978).

Certain elements were common in these experiments. First, all used introductory courses in marketing management. Second, the participant work loads were similar (100 to 135 hours). Third, grades for natural learning participants were not based on the instructors' evaluations. Where grades were required (Wharton and Hawaii), they 
were determined at the start of the course for SOS (with all receiving the same grade), and they were based on the time in the time contract.

The experiments also differed in many ways. Three institutions were involved: the Swedish Institute of Management (IFL), the Wharton School, and the U. of Hawaii. The IFL was for executives while the others were for MBAs. Programs varied from two weeks at the IFL to 15 weeks at Wharton. The traditional program used "teaching-by-objectives," lecture/discussion, or the Harvard case method. Natural learning used SOS or time contracts.

\section{Criteria}

A variety of criteria were used. Data for these criteria were obtained primarily from an end-of-course questionnaire and a six-month critical incidents mail survey.

The critical incidents survey was of particular importance because it measured long-term behavioral change. It asked for descriptions of specific situations where the participant acted differently because of the course.

The cover letters for the critical incidents surveys were signed by an administrator in all cases except Hawaii (where I signed it). The letters said that the study was assessing the effectiveness of the course, not the professor.

Responses to the critical incidents survey were initially coded by three assistants who received general instructions (Appendix B). All coders were blind with respect to the hypotheses. Furthermore, the identity of participants and instructors was removed from the replies. Each coder worked independently.

Coders differed greatly on specific incidents. Was it an attitude or behavior change? How important was it? To overcome coding problems, five additional coders were hired. They were given more specific instructions (Appendix B). Each of them, working independently of one another, coded responses from the seven experiments. The order that the experiments were coded was varied systematically among these assistants.

The experiments are described here in chronological order. After a brief description of the experimental design, consideration is given to problems in implementing each experiment. The results are then presented.

\section{Sweden 1974}

The first experiment was run at the Swedish Institute of Management (IFL) in 1974. (The IFL is associated with the Stockholm School of Economics). The participants were 17 middle managers sent by companies in Sweden. The program met for six two-week sessions in an 11-month period.

Participants requested either the natural learning or traditional groups at the start of the course. Although most requested natural learning, they were split into two groups based on the strength of their preference. To help in evaluating the experiment, all participants were asked to keep diaries on what they did and learned.

To create an experimental atmosphere, teaching by objectives was used in the traditional group. They were called a PSI (Personalized Student Instruction) group and were given copies of a paper using some elements of PSI (Chentnik and Weatherford, 1974). (This design element, making each group "experimental," is of minor importance according to research by Sigall, Aronson, and van Hoose (1970). They found no evidence for the Hawthorne effect. Faculty members completed questionnaires on objectives. Replies were provided to all participants. The learning tasks consisted of cases, lectures, and discussions. Self-administered exams were scheduled after most sessions.

The SOS approach was used for natural learning. Each SOS participant wrote objectives two months before the 2-week marketing course. He was asked to attend only sessions relevant to his objectives and to create alternative tasks if necessary. Also, he was asked to write a review for each task, keep a diary, write an end-of-course review, and write a plan for applications after the course. 
Implementation: Implementation problems in the traditional group were serious. Although 8 out of the 9 faculty completed questionnaires for the objectives on each class, the quality was not high. Most faculty said it was difficult for them to state objectives. Furthermore, participants made little effort to understand the instructors' objectives. Follow-up exams were not completed after each session. Still, some success was achieved for the traditional group; for example, 7 of the 9 participants reported that the examinations were "useful" or "somewhat useful."

Although SOS participants reported spending an average of 16 hours for planning, only 4 of the 8 respondents felt their planning was "quite successful"; 2 reported no success. The quality of the plans was not high, in my opinion. The objectives were vague and most participants did not provide a timetable. Also, the review process was not always followed and planning of applications was vague.

Despite problems, the traditional and SOS groups differed substantially. Four of the eight SOS participants wrote diaries, but none of the nine traditionals did. Final course reviews were written by four SOS participants vs. none by the traditionals. Furthermore, all 8 SOS members attended the final review session vs. 4 of the 9 traditionals. (All differences significant at $\mathrm{p}<.05$ using the Fisher Exact Test.) In addition, the SOS participants said that they had never before been through a similar program in their formal education (a comment that carried through in all of the natural learning experiments).

Results: Participant questionnaires provided ratings of "amount learned." The combined average for traditional and SOS participants was 3.6 (scale from $1=$ "not good at all" to $5=$ "outstanding"). This rating exceeded the ratings of 3.2 and 3.1 from participants in the two preceding IFL marketing courses ( $p<.05$ using the median test). When asked if the marketing program "was more successful or less successful than your previous efforts at IFL," SOS respondents averaged 3.6 (with 5 being "much more successful") vs. 3.1 for the traditionals.

With three mail and one phone follow-ups on the critical incidents survey, responses were received from all participants. Replies were coded by three assistants with general instructions (Appendix B).

SOS participants reported 1.5 behavioral incidents, while traditionals reported 0.4 incidents. For "large behavioral changes," the number of incidents was smaller, yet SOS was better (0.8 incidents vs. 0.3). Similarly, for large "job-related" changes, SOS respondents were superior (0.5 vs. 0.2). Finally, SOS reported more attitude change (0.6 vs. 0.4).

The five coders with specific instructions (Appendix B) found fewer behavioral changes in total, but, as before, more behavioral change was reported for SOS (0.8 vs. 0.3 incidents). Each of the five coders found SOS to be superior for "all behavioral changes" and four found it superior for "large behavioral changes" and for "attitude changes."

\section{Sweden 1975}

The second experiment, run at IFL in 1975, had 32 participants. They were middle managers with backgrounds similar to those in Sweden 1974. Participants did not initially select an educational strategy; instead, SOS was made available to all. The determination of whether one followed SOS was made from an end-of-course questionnaire.

More emphasis was placed on the SOS objective setting in Sweden 1975 than in Sweden 1974. This process was completed three months before the marketing course began. More emphasis was also placed on the programming phase. Participants developed an explicit timetable by choosing from a "resource bank" of 25 scheduled but optional sessions taught by seven faculty, audio tapes, readings, and a collection of 28 self-directed exercises. (The self--directed exercises were designed for individual or group use.) The individual work plans were completed one month before the marketing course.

Implementation: Implementation of Sweden 1975 was more successful than Sweden 1974. Participants reported spending 20 hours for planning. All but one participant wrote a statement of objectives. Most participants 
developed a time plan. On the other hand, many respondents had difficulty following their plan, and the review phase was often omitted.

The experimental program provided a greater opportunity for participants to take responsibility according to a survey of the five core faculty (all checked " 5 " on the 1 to 5 scale). Furthermore, faculty said the participants did take responsibility (all checked a "4").

An end-of-course questionnaire, completed by all but two participants, contained questions on responsibility and success in setting objectives, scheduling learning tasks, and review. These were summed for each individual to yield a "natural learning index." The 15 highest respondents were called SOS participants and the other 14 were traditionals. The SOS participants also made more plans for applications (2.2 vs. 0.8).

Results: Participant ratings of how much they learned was 3.5 (scale from $1=$ "not at all good", to $5=$ "outstanding"). This was about the same as the satisfaction of 3.6 for Sweden 1974, and the 3.4 that these participants gave to other courses in their 12-week program.

For attitude change, 270 of the SOS respondents said they improved their planning skills "a great deal" vs. 70 of the traditionals. For learning skills, 130 of SOS respondents said they improved "a great deal" vs. none of the traditionals.

The critical incidents survey, with two mail and one phone follow-ups, yielded replies from all but one each of SOS and traditional participants. The replies were coded by three assistants (one of whom also coded Sweden 1974), using the general instructions. SOS respondents reported 2.3 behavioral incidents and the traditionals only 0.6. When only "large job changes" were considered, SOS was superior by 0.7 to 0.1 .

The coding was repeated by the five coders with specific instructions (Appendix B). Again, SOS was substantially better on behavior change ( 0.9 vs. 0.3$)$, on large behavior changes $(0.2$ vs. 0.0$)$, and on attitude changes (1.0 vs. 0.4$)$. SOS was superior for all criteria for each coder.

\section{Wharton 1975}

This experiment was run in a 4-month-MBA course in Fall 1975. One of the five sections was run by the author using SOS. The others were run by four instructors using a traditional lecture/discussion approach. Students selected sections based on their schedules and on the reputation of the faculty. Initially, participants transferred among various sections. Half who examined natural learning stayed. This left 48 natural learning participants and 145 in the four traditional sections.

The SOS course design was similar to Sweden 1975. The resources were 25 scheduled group exercises, 31 self-directed exercises, and cooperation by the Wharton Communications Department for oral and written communication skills.

Implementation: Completion of SOS was defined by the punctual submission of three reports covering objectives, learning tasks, review, and applications. (Three of the 48 participants failed this definition, but to be conservative they were retained in the analysis.) I judged the quality of most reports to be good.

SOS participants reported taking responsibility for the objective setting, learning tasks, and review. As in Sweden 1975, they reported moderate success with the first two steps, but they had more success with the review. They were not as ambitious in planning applications, with only 0.9 applications, but traditionals planned only 0.05 . SOS participants felt responsible for their learning: 64\% rated themselves at "5" (on a 1 to 5 scale) vs. $24 \%$ for traditionals.

Results: Participant satisfaction from the end-of-course evaluation was 4.0 for SOS participants (scale of $1=$ poor to $5=$ excellent) vs. 3.7 for the traditional sections. The groups did not differ on how much they thought they learned. 
A common mid-term exam was required. It was used for grading traditionals. The exam was given to all participants at the same time and was blind-graded by assistants hired for this purpose. The exam was not ideal because many SOS participants left early. The SOS median grade $(n=48)$ was 17 , slightly lower than the median of 18 for the traditionals $(\mathrm{n}=138)$. This difference was statistically significant $(\mathrm{p}<.05)$ : SOS participants did poorer on short-term gains in knowledge.

An end-of-course attitude survey was used in the SOS section $(n=44$, response rate of $92 \%)$ and in two traditional sections $(n=64$, response rate of $70 \%)$. "A great deal" of improvement in planning skills was reported by $28 \%$ of SOS respondents vs. $6 \%$ for traditionals. For improving one's ability to learn, $20 \%$ of SOS respondents said they improved "a great deal" vs. none of the traditionals. These short-term attitude changes were statistically significant $(\mathrm{p}<.05)$ in favor of SOS.

Attitude change was also measured by a before/after questionnaire. The "before" version was completed prior to the objective setting phase, and the "after" version was completed on the last day of the marketing course. This 27 -item questionnaire asked whether respondents agreed ( $1=$ "disagree strongly" to 5 = "agree strongly") on items such as "competition should be encouraged in all businesses," "I would like to be a marketing manager," "I have an excellent understanding of the role of a marketing manager," and "I feel confident that I can handle complex marketing problems." Changes were compared with the direction advocated by the faculty and resource materials. Usable responses were obtained from $82 \%$ of the SOS participants and $41 \%$ of the traditionals. For the 39 SOS respondents, $47 \%$ of the items moved significantly toward the desired end of the continuum, and $11 \%$ were significantly in the opposite direction. For the 47 traditional respondents, $36 \%$ of the changes were significantly positive and $16 \%$ were significantly negative. This short-term attitude change among SOS participants was significantly more positive than that of traditionals $(\mathrm{p}<.05)$.

The critical incidents survey, using three mail and one phone follow-ups, yielded responses from 37 SOS participants ( $80 \%$ response) and 105 traditionals ( $77 \%$ response). The responses were coded by three new research assistants using the general instructions.

SOS participants averaged 1.4 behavioral incidents vs. 0.9 for traditionals. SOS was also superior for large behavioral changes, although few incidents were reported ( 0.08 vs. 0.04$)$, and for attitude changes ( 0.8 vs. 0.5$)$.

Coding with specific instructions yielded similar results. Each coder rated SOS superior for behavioral changes. Four coders found SOS superior on large behavioral changes (the 5th had a tie). Three coders found more attitude changes for SOS.

\section{Wharton 1976}

The design for Wharton 1976 was similar to Wharton 1975, although improvements were made in learning tasks. One section was run by the author using SOS. The other two sections were run in a traditional manner by two faculty members (one of whom was in Wharton 1975) using lectures and discussions. Participant selection of sections was similar to Wharton 1975. The SOS section had 51 participants and the two traditional sections had 80.

Implementation: All but one of the SOS participants completed the course. Ratings of the extent to which they took responsibility and their success for the steps in the learning process were similar to Wharton 1975.

Results: Participant ratings were obtained by an end-of-course questionnaire. The $41 \mathrm{SOS}$ respondents rated the course at 3.6 vs. 2.9 for 68 respondents from the two traditional sections $(\mathrm{p}<.05)$.

On the common mid-term exam, required for all participants, SOS participants again displayed little interest and left the exam early. SOS scored lower than traditionals (10.7 vs. 11.7).

The end-of-course survey was completed by 45 SOS participants ( $88 \%$ response) and by 51 traditionals (75\% response). A "great deal of improvement in planning skills" was reported by $36 \%$ of the SOS respondents vs. $8 \%$ of traditionals. For "improving learning skills," $22 \%$ of SOS respondents. said they improved "a great deal" vs. $8 \%$ of traditionals. These short-term attitude changes were each significant in favor of SOS $(p<.05)$. 
The critical incidents survey (Appendix A) was constrained because few addresses were available for the graduates. As a result, the follow-up was limited to participants still at Wharton. Despite 3 mail follow-ups, only $51 \%$ of the SOS participants and $27 \%$ of traditionals responded. The replies were coded by two new assistants using the general instructions. SOS respondents averaged 1.1 incidents vs. 0.4 for traditionals. SOS respondents reported more large behavioral changes ( 0.3 vs. 0.03$)$ and more attitude changes ( 0.9 vs. 0.7$)$.

When the critical incidents were coded with specific instructions, SOS was superior for each coder for behavioral change; it was superior for 4 of the 5 coders for large behavioral changes (with one tie); and it was superior for attitude changes for 3 of the 5 coders.

\section{Hawaii 1976}

Hawaii 1976 was a required course in the U. of Hawaii MBA program in Spring 1976. I was the only faculty member. The design was similar to Wharton 1976. Participants were classified at the end of the course as SOS or traditional based on my judgment on how closely they followed SOS.

Implementation: Of the 20 participants who started the course, 19 completed it. Participants differed greatly in the extent that they used SOS. In my judgment, five participants made extensive use of SOS and eight made moderate use.

Results: The follow-up critical incidents survey (Appendix A) with three mail and one phone follow-ups, yielded responses from 16 of the 19 participants. The responses were coded by three new assistants using the general instructions. The SOS participants were superior on large behavioral changes, all behavioral changes, and attitude change for each of the three coders using the general instructions. SOS averaged 3.3 behavioral incidents vs. 1.2 for the traditionals; for large changes SOS was superior (0.6 to 0.1$)$.

All five coders using the specific instructions found SOS superior on all behavioral changes as well as for only large behavior changes. Four of the five coders found SOS superior on attitude changes.

\section{Wharton Control}

An alternative explanation for the above experiments is that the methods for selecting the "natural learners" were merely selecting the "best learners." In other words, these natural learners would learn better in any program. Another possible explanation is that the natural learners are better at "psyching out" what is needed on critical incidents surveys.

Wharton control tested these alternatives. Natural learners were identified in these courses. If the alternative explanations were true, these natural learners would report more behavioral change. In contrast, the natural learning hypothesis argues for negligible differences because the Wharton Control course was based on teacher responsibility: Natural learners would do better only in a course utilizing natural learning principles.

Implementation: Two sections of an MBA course in Spring 1979 were used for the Wharton Control. They were taught in the traditional manner by an instructor who is regarded by many as the best teacher in the marketing department. He used the Harvard case method.

The end-of-course questionnaire was used to identify natural learners, using the same "natural learning index" as in Sweden 1975. Significant differences were reported by participants in the extent to which they took responsibility for and were successful with objective setting, scheduling learning tasks, and review. Those reporting themselves as high in responsibility $(\mathrm{n}=46$ ) averaged 3.8 (on the 1 to 5 scale) while those low on this scale $(\mathrm{n}=53$ ) scored 2.4. This was comparable to the responsibility ratings for the groups in Sweden 1975.

Results: For the critical incidents survey, addresses were obtained for 122 of the original 135 participants. Three mail follow-ups yielded responses from 99 participants, an $81 \%$ response rate. Three respondents had not 
completed the end-of-course questionnaire, leaving 96 usable responses. The responses were coded only by the five coders with specific instructions.

The alternative hypothesis was rejected: Those identifying themselves as higher in learner responsibility did not report more behavioral change; in fact, they reported less change ( 0.3 vs. 0.4 incidents). Furthermore, they did not report more large changes nor more attitude change. These results are consistent with the natural learning hypothesis: The course must provide an opportunity for natural learning to take place.

\section{Time Contracts}

The preceding experiments did not examine which factors in SOS are most important. As a rough assessment, time contracts were used as an alternative to SOS. The time contracts recommended natural learning principles. However, the requirements were simpler: Completion of the course and the grade were based solely on the time spent. As proof, participants were required to keep a daily record of time spent, what they did, and what they learned. One requirement for this diary was that participants should not evaluate things outside themselves. In the Fall 1979 group, an additional requirement was imposed: Participants had to prepare a written schedule of their learning tasks.

Implementation: Participants could choose either the time track, SOS, or the traditional approach in an MBA course that I taught at Wharton in Summer 1978. The time contract was more popular than SOS: $74 \%$ of the 42 participants selected it. In the Wharton Fall 1979 experiment, the choice was limited to time contract or traditional; all but one of the 31 participants selected the time contract initially. Of these, 30 completed the time contract.

On an end-of-course survey in the Fall '79 group, time contract participants reported feeling more responsible for their learning here than in their traditional courses $(\mathrm{p}<.10)$.

Results: The end-of-course questionnaire was completed by 59 of the 73 participants in the 1978 and 1979 groups. Those using time contracts reported more success at changing behavior than in their traditional courses ( $\mathrm{p}<$ $.01)$. They also reported more attitude change $(\mathrm{p}<.01)$. They did not report learning more content. On average, satisfaction was no different than with their typical courses; however, some participants were strongly negative.

Responses for the 6-month critical incidents surveys were obtained from 32 of the 60 time contract participants ( $53 \%$ response rate) by using three mail follow-ups. These responses were coded only by the five assistants using specific instructions. They reported 1.0 incidents, almost as much as the SOS participants in the previous experiments. (A more complete description of the time contract studies, including its use in three courses other than marketing management, is provided in Armstrong, 1980.)

\section{Alternative Explanations}

The seven experiments ruled out some, but not all alternative explanations. One reasonable alternative is that practice in the review writing process made natural learners better at writing about changes on critical incidents surveys. However, the prior research, which supported natural learning (especially Miner, 1965; Schmuck, 1968; and French, Kay and Meyer, 1966), did not utilize practice in writing reviews. Furthermore, traditional participants in Sweden 1975 and Hawaii 1976 also received practice in the review phase but this did not change the results.

Natural learning calls for learner responsibility for the key phases of learning: setting objectives, selecting learning tasks, reviewing, and planning applications. Previous research suggested that natural learning produces more behavioral change than the traditional strategy (based on teacher responsibility). This hypothesis received support from seven field experiments conducted from 1974 through 1979. These experiments involved 15 groups with 368 participants. The superiority of natural learning was found when differences were made in:

a) institutional settings (Wharton, Stockholm, and Hawaii; executive and MBA Programs; short vs. long courses), 
b) faculty (15 faculty members),

c) implementation of the traditional strategy (teaching-by-objectives, lecture/discussion, or Harvard case method),

d) implementation of natural learning (SOS or time contracts),

e) identification of natural learners (prior selection by participants, end-of-course responses by students, or opinions of the instructor),

f) criteria (all behavioral changes; large changes; large job related changes),

g) coders (18 were used), and

h) coder instructions (general vs. specific).

Long-term behavioral changes, summarized in Exhibit 5, were more than twice as likely with natural learning. This superiority of SOS is unlikely to have occurred by chance $(\mathrm{p}<.01)$, with a one-tail sign test using the first five experiments and the Wharton Control vs. Wharton Time Contract as a sixth comparison). The gains were achieved at no added cost to the institutions.

Attitude change was also greater among the natural learning participants. On the end-of-course questionnaires, they reported more change in improving their "learning" and "planning skills." On a before/after survey, natural learners reported developing a more positive attitude toward marketing. On the critical incidents survey, natural learning participants reported more attitude changes.

No differences were expected for short--term changes in knowledge. The results, based on two exams, suggested that natural learners did poorer.

Participant satisfaction did not differ between SOS and traditional respondents on average. However, SOS did have a few "hostile, alienated objectors."

The natural learning hypothesis, based on prior research, was supported by seven field experiments. Two alternative hypotheses, that the method merely identified the better learners or that the "natural learners" were better at writing about behavioral change, were ruled out by the Wharton Control experiment.

\section{References}

Ammons, R.B. (1965), "Effects of knowledge of performance: A survey and tentative theoretical formulation," Journal of General Psychology, 54, 279-299.

Armstrong, J.S. (1976), “The Panalba role playing case,” in K. L. Bernhardt (ed.), Marketing: 1776-1976 and Beyon., Chicago: American Marketing Association.

Armstrong, J.S. (1977a), "Designing and using experiential exercises," in M. W. DeLozier, et al. (eds.), Experiential Learning in Marketing Education. Columbia, SC: Division of Research, College of Business Administration, U. of South Carolina.

Armstrong, J.S. (1977b), "Forecasting the air travel market," in M. W. DeLozier, et.al. (eds.), Experiential Learning Exercises in Marketing. Santa Monica, CA: Goodyear.

Armstrong, J.S. (1978), Long-Range Forecasting: From Crystal Ball to Computer. New York: Wiley Interscience. [in full text on forecastingprinciples.com] 
Armstrong, J.S. (1980), "The use of time contracts in formal education," in D. C. Brenenstuhl and W. D. Biggs (eds.), Experiential Learning Enters the 80s. Tempe: College of Business Administration, Arizona State U.

Attiyeh, R. and Lumsden, K.G. (1972), "Some modern myths in teaching economics: The U.K. experience," American Economic Review, 42, 429-433.

Baumhart, R. (1968), Ethics in Business. New York: Holt, Rinehart and Winston.

Berg, I.(1970), Education and Jobs: The Great Training Robbery. New York: Praeger.

Blumberg, P. (1968), Industrial Democracy: The Sociology of Participation. New York: Schocken Books.

Chentnik, C.G. and Weatherford, P.A. (1974), “Teaching management by management exception,” Academy of Management Journal, 17, 90-100.

Colgrove, M.A. (1968), “Stimulating creative problem solving: Innovative set,” Psychological Reports, 22, 1205-1211.

Condry, J. (1977), “Enemies of exploration: Self-initiated versus other-initiated learning,” Journal of Personality and Social Psychology, 35, 459-477.

Costin, F., Greenough, T. and J. Menges (1973), "Student ratings of college teaching: Reliability, validity, and usefulness," Review of Educational Research, 41, 511-535.

Dubin, R. and Taveggia, T. C. (1968), The Teaching-Learning Paradox. Eugene, OR: Center for Advanced Study of Educational Administration, U. of Oregon.

Duchastel, P.C. and Merrill, P.F. (1973), "The effects of behavioral objectives on learning: A review of empirical studies," Review of Educational Research, Winter, 43, 53-69.

French, J. R. P., Kay, E., and Meyer, H. H. (1966), "Participation and the appraisal system," Human Relations, 19, 3-19.

Gage, N.L. (1977), The Scientific Basis of the Art of Teaching. New York: Teachers College Press, Columbia U.

Gutteridge, T.G. (1973), "Predicting career success of graduate business school alumni," Academy of Management Journal, 16, 129-137.

Hoyt, D.P. (1966), “College grades and adult achievement: A review of the literature," The Educational Record, 47, 70-75.

Jencks, C. (1972), Inequality: A Reassessment of the Effect on Family and Schooling in America. New York: Basic Books.

Kolb, D.A. and Boyatis, R.E. (1971), "Goal setting and self-directed behavior change," in D.A. Kolb, et. al. (eds.), Organizational Psychology: A Book of Readings. Englewood Cliffs, Prentice Hall.

Kolb, D.A., Winter, S. and Berlew, D. (1968), "Self-directed change: Two studies," Journal of Applied Behavioral Science, 4, 453-473.

Lepper, M.R., Greene, D. and Nisbett, R.E. (1973), "Undermining children's intrinsic interest with extrinsic rewards: A test of the overjustification hypothesis," Journal of Personality and Social Psychology, 28, 129-137.

Levine, F.M. and Fasnacht, G. (1974), “Token rewards may lead to token learning,” American Psychologist, 29, 816-820. 
Locke, E.A. (1968), "Toward a theory of task motivation and incentives," Organizational Behavior and Human Performance, 3, 157-189.

Luthans, F., Walker, J.W., and Hodgetts, R.M. (1969), "Evidence on the validity of management education," Academy of Management Journal, 12, 451-457.

Marks, R.B. and Molander, J.D. (1977), "Student evaluation - A measure of validity in the introductory marketing course," in American Marketing Association Proceedings.

McCord, J. (1978), “A thirty-year follow-up of treatment effects,” American Psychologist, 33, 284-290.

McFall, R.M. (1970), "Effects of self-monitoring on normal smoking behavior," Journal of Consulting and Clinical Psychology, 35, 135-142.

McKeachie, W.J. (1969), Teaching Tips: A Guidebook for the Beginning College Teacher. Lexington, Mass.: D.C. Heath.

Miller, D.W., "Dangers of using student evaluation for administrative purposes," Collegiate News and Views, 1978, 2-3.

Miner, J.B. (1965), Studies in Management Education. New York: Springer.

Naftulin, D.H., Ware, J.E., Jr., and Donnelly, F.A. (1973), “The Doctor Fox lecture: A paradigm of educational seduction," Journal of Medical Education, 48, 630-635.

Newton, J. R. (1965), “Judgment and feedback in a quasi-clinical situation,” Journal of Personality and Social Psychology, 1, 336-347.

Powell, R.M. and Davis, C.S. (1973), “Do university executive development programs pay-off?” Business Horizons, August, 16, 81-87.

Price, P.B., Taylor, C.W., Richards, J.M., Jr., and Jacobsen, T.L. (1964), "Measurement of physician performance," Journal of Medical Education, 39, 203-211.

Rodin, M. and Rodin, B. (1972), “Student evaluations of teachers," Science, 177, 1164-1166.

Schmuck, R.A. (1968), "Helping teachers improve classroom group processes," Journal of Applied Behavioral Science, 4, 401-435.

Scott, W.A. (1957), "Attitude change through reward of verbal behavior," Journal of Abnormal and Social Psychology, 55, 72-75.

Sigall, H., Aronson, E., and van Hoose, T. (1970), “The cooperative subject: Myth or readlity?” Journal of Experimental Social Psychology, 6, 1-10.

Valiquet, M.I. (1968), "Individual change in a management development program," Journal of Applied Behavioral Science, 4, 313-325.

Walker, D.F. and Schaffarzick, J. (1974), “Comparing curricula," Review of Educational Research, Winter, 44, $83-111$.

Weinstein, A. G. and Srinivasen V. (1974), "Predicting managerial success of master of business (MBA) graduates," Journal of Applied Psychology, 59, 207-212. 
Wolfe, J. (1975), “A comparative evaluation of the experiential approach as a business policy learning environment," Academy of Management Journal, 18, 442-452.

Zelby, L.W. (1974), “Student-faculty evaluation,” Science, 188, 1267-1270. 


\section{APPENDIX A}

\section{Follow-Up Survey*}

1. Try to think of one or more incidents where your behavior in other courses, or in any job you may have was influenced in some way by your experience with [the course]. In other words, was there a "decision" or a "situation" or a "problem" where you felt that you handled things differently due to your experiences during [the course]. Please describe the incident. If there was more than one incident, describe the additional ones also. Say what you did and how you felt that your behavior was different. (If you cannot think of any incidents, write "none.")

2. Now, can you think of any incidents where your behavior in your personal life (e.g. career planning, your family, extra-curricular activities, or your local community) was influenced in some way by your experience with [the course]? Please describe the incident. If there was more than one incident, describe the additional ones also. (If you cannot think of any incident, write "none.")

\footnotetext{
* This survey was sent out on two pages.
} 


\section{APPENDIX B}

Name of the Coder

Date

Coding Sheet for Critical Incidents Survey

Coder's Instructions: Please read the responses to questions relating to "on-the-job" and to "personal life" and record all items that are critical incidents. Use the following categories (read these carefully and keep them in mind as you go through each response).

If a reported change has not yet been actually started, then code this as an attitude change. That is, it's an attitude change if it still only exists in the mind of the respondent. Also, please record each incident separately using an "B" for a change which seems "large" or very important; an "M" for a change of "moderate" importance; and an "S" for a small change. Use "0" if the item does not represent a change, and a "dash" if nothing was written or if the word "none" appears. (There should be an entry for each space in the table.)

Note that we are concerned about critical incidents. Incidents represent specific and well defined events. People should be able to cite a specific happening to qualify as an incident.

To qualify as behavior, the description should describe physical action. Mental actions are attitude changes.

Remember that a given incident is coded only once (either as an "attitude change" or as a "behavior change," and either "on-the-job" or "off-the-job").

\section{Notes to Appendix B:}

1) The first two paragraphs are the "general instructions." The last three paragraphs were added to the "specific instructions."

2) Each coder worked independently.

3) All coding was blind. That is, the coders did not know the hypotheses and the replies did not contain any information about the identity of the respondent or the instructor. 